\title{
The Dialogue: an Essential Component to Consider "Organization as a Community of Persons"
}

\author{
Marie-Noelle Albert ${ }^{1}$ (D) Jean-Pierre Perouma ${ }^{1}$
}

Received: 27 September 2016 / Accepted: 22 June 2017 / Published online: 17 July 2017

(C) Springer International Publishing AG 2017

\begin{abstract}
Even if the concept of "community of persons" is more and more present, only a few studies with practical cases actually use it. This paper is based on the pragmatic constructivism epistemological paradigm and uses an autopraxeography method from a previous action research study. The case presented concerns part of a large business. At the beginning of our study, this organization experienced many conflicts. The intervention we implemented developed dialogues and built a community of persons. At the end of this story, a new HR manager arrived and decided to stop what was previously implemented (to increase productivity), putting an end to the dialogues and all of the collaboration that went along with them. This way of doing leads to fake productivity because it generates a lot of hidden costs. Thus, this case shows that a dialogue is necessary to build a community of persons, and vice versa. Otherwise, there are just associations of individuals.
\end{abstract}

Keywords Community $\cdot$ Persons $\cdot$ Constructivism $\cdot$ Self-studies $\cdot$ Autopraxeography

\section{Introduction}

Melé (2016), in his fifth proposition, explains that humanism highlights both individual autonomy and sociability. This proposition develops implicitly the idea of a community of persons that contrasts with a vision of dehumanized organizations, which implies that businesses are just a set of contracts and that their main finality is to enrich their owners (Melé 2009b; Melé 2013). If we understand organizations as a community of persons, we can gather information on organizational phenomena as, for instance, shared knowledge (Melé 2009b). These persons need to have a dialogue with other persons. Naughton (2015) explains that

Marie-Noelle Albert

marie-noelle_albert@uqar.ca

Jean-Pierre Perouma

jean-pierre_perouma@uqar.ca

1 University of Quebec at Rimouski, Rimouski, Canada 
further research should focus on the concept of "community of persons for the common good" (p. 197). He recommends that such studies place an emphasis on case studies. This is the starting point of our paper, which is itself based on a case: the human resources manager of this organization knew that there was a lack of dialogue and wanted to develop it. A dialogue is a discussion built over time between several persons, and it is a necessary component of a community of persons.. The etymology of the word refers to the ancient Greek prefix $\delta$ ió, meaning "through" and $\lambda o ́ \gamma o \varsigma$ meaning "word" or "reason." Dialogue is therefore a word that runs through and provides a vehicle for transmission; it reflects the movement of ideas and the direction that evolves.

The purpose of this paper is to deepen our understanding of a community of persons, especially of the dialogues in these communities. We start by defining the concept of community of persons. Then, we present our methodology, and finish with the case and reflexive work.

\section{Organizations as a Community of Persons}

While this expression is not usual in managerial literature, organizations can be viewed in some cases as a community of persons.

First, we present our definition of a person in order to clearly explain how organizations can be considered as communities.

\section{$\operatorname{Person}(\mathbf{s})$}

Like Melé (2012) and Fortier and Marie-Noëlle (2015), we use "person" (even in the plural form) to take into account the wealth of meaning that underlies this word, which comes from the Greek prosôpon. At the beginning, prosôpon (Housset 2007) meant the face, then the meaning expanded to encompass the mask worn by an actor, and then it became synonymous with the social person. So, prosôpon means a face, a thing, an individual in the flesh, or a concrete individual who is playing a role (Housset 2007). It is what others see of the self and of its identity. Latin developed the use of persona, which moved from the mask to the character and from the character to the bearer of a word (Vernant 1996). This concrete individuality — his or her identity-makes a person a unique being. A person is both unique and multifaceted, different from others. Hence, a person cannot be understood by observing only one facet, and although grasping all of them may seem difficult, researchers and specialists must keep in mind a person's multifaceted composition. A person is not an object that we can divide up and watch (Mounier 1952). Mounier (1952: xvii) explains his definition of a person:

One might expect that personalism would begin by defining the person. But one can only define objects exterior to man, such as can be put under observation. Here is my neighbour. He has a unique feeling of his body, which I cannot have; but I can look at this body from without, examine its dispositions, its heredity, its form, its maladies; in short, I can treat it as an object of physiological, medical, or other knowledge. He exercises functions, and there is a functional order and a functional psychology, which I can apply to the study of his case, although they are not he, the whole man in his total reality. Moreover, and in the same way, he is a Frenchman, a bourgeois, a socialist, a Catholic, etc. But he is not a Bernard Chartier, he is Bernard Chartier. The thousand 
ways in which I can distinguish him, as an example of a class may help me to understand him, and above all to make use of him, they show me how practically to behave towards him. But these are merely sections taken, in each case, through one aspect of his existence.

A person is therefore unique without being reduced to a category and being understood only in an individualistic way.

Indeed, the notion of "person" rests more specifically on personalism. Despite the latter's heterogeneous perspective, personalists agree on a person's uniqueness and dignity (Melé 2009a). More precisely, personalism differs greatly from any other form of collectivism since a person retains autonomy and individual freedom when in a community. A person is not only an individual who can simply be counted as part of a community, but also a unique being that can neither be replaced nor viewed as an abstraction (Melé 2009a). A person also differs from an individual, because a person is not seen as someone leading an isolated existence, linked to others solely through a social contract. On the contrary, a person is seen as a social being intrinsically related to others and leading an interdependent existence (Melé 2009a). The ethical personalist opposes the Other to one's Self, aiming to obtain from the Other an ethical answer with the same intensity and sharing the same openness. In this reciprocity, moral obligation transforms into moral love. The first stops when one's own obligation is met, and the second is a tension that solicits the Other, thus attracting him or her toward a creative answer (Attilio and de Nicola 1989). In this process, a person is not led by principles deduced abstractly, but by the fulfilment of the Other and the quality of the relationship in a way that makes a person want to create (Danese and Dinicola 1989). In addition, a person is a complex being interacting with other complex beings in a complex environment. Therefore, it may help us to use complex thinking (Morin 2008) to understand communities of persons. Morin (2008) demonstrates that a person can be altruistic and selfish, as well as nice and mean to others. Consequently, it is possible for selfishness to inhabit a person who is nonetheless opening up to others. Instead of denying this phenomenon, being aware of it and taking it into consideration might be preferable. Although the notion of "person" connotes uniqueness and dignity, the word "individual" is often preferred (Melé and Gonzalez Canton 2014) in some countries.

\section{An Organization as a Community of Persons}

According to Melé (2012) “a 'community of persons' emphasizes both individuals and the whole" (p. 89). Mintzberg (2009) explains that individualism is a beautiful idea because it produces incentives, promotes leadership, and fosters development. However, persons are also social animals and need social glue to unite them for their own good. This is what Mintzberg (2009) calls "community." Community entails taking care of work, colleagues, and one's place in the world. Mintzberg positions community spirit between individualistic leadership, on the one hand, and collective citizenship, on the other. This view of a community is very similar to the one that Melé (2009a) describes, in which persons share common goals and goods belonging to the community while maintaining their sense of individuality. Naughton (2015) explains that organizations can be viewed as a continuum between an association of individuals and a community of persons, even if these two notions could be used interchangeably in everyday language. If we view the organization as an association of individuals, we consider it as an aggregate of individuals who are mostly motivated by their own goals and calculations, 
and bonded by contracts. This point of view uses only economic and legal human conceptions. With a community of persons, there is a move from a "me" to a "we" (Naughton 2015).

Organizations as communities endeavour to stimulate the good in each person who is its member (Tablan 2014). "Providing a safe working environment free from harassment, bullying, and discrimination is necessary but not sufficient for a genuine community. Rather, workers and managers must try, in the course of their common endeavours, to build authentic human relationships that transcend the limits of their employee-employer contract" (p. 12).

Tönnies (1887) distinguishes two ideal types: Gemeinnschaft and Geesellschaft. The first one could be translated as "community" and the second one as "society." Tönnies (1887) opposes societies and communities. Societies are just based on individuals' utilitarian interests and communities assume an emotional social function based on emotional feeling. Such communities are characterized by emotional and special proximity where human relationships are authentic. In these communities, the whole takes priority over individuals. Tönnies (1887) promotes this ideal-type. Societies support a mechanical and egoistic system that does not consider a person as a social human being that could be open to others. Tönnies' (1887) notion of community does not allow us to recognize the existence of each person. Adler et al. (2008), for their part, distinguish three kinds of communities: Gemeinschaft, Gesellschaft, and collaborative. In the first one, coordination relies on traditional norms. The second has a coordination mechanism that is based on market price and hierarchical authority. The third, a collaborative community, is based on interdependent self-construal, that is, each participant coordinates his or her activities through a shared commitment to a set of finalities. "The procedures are designed collaboratively and used by peers to monitor each other and to work together to improve performance" (Adler et al. 2008, p. 366). Our perspective is that a community of persons is a collaborative community in which persons respect and are openminded toward one another. Since it leads to being more productive, this cannot be a naïve way of thinking about organizations. According to Melé and Gonzalez Canton (2014), "business as a community of persons is a view of the organization [...] and entails recognizing the organization as a real entity made up by free and autonomous persons. This latter form a whole, based on common goals, interconnectedness, interdependence, loyalties and even moral commitments" (p. 193). Of course these communities are not only composed of persons who work in the same organization, they are also developing a business as a community rather than an association. This should have a positive impact on persons and the organization. We study a practical case that enlightens us on this concept of community of persons.

\section{Methodology}

In this article, we use action research in a pragmatic constructivism epistemological paradigm. First, we present the specificities of this epistemology, and then the methodological particularities. We used an autopraxeography method based on an action research study conducted previously. This process is shown schematically in Fig. 1. At the beginning there is an organization problem (in our case, this is an organization with many internal conflicts). In a previous action research process, we made observations, held meetings and interacted with the various persons in this organization; in so doing, we produced local knowledge. In the autopraxeography process, reflective work and reflexive work are carried out during the action research experience, using a large body of academic literature, in order to produce generic knowledge. 


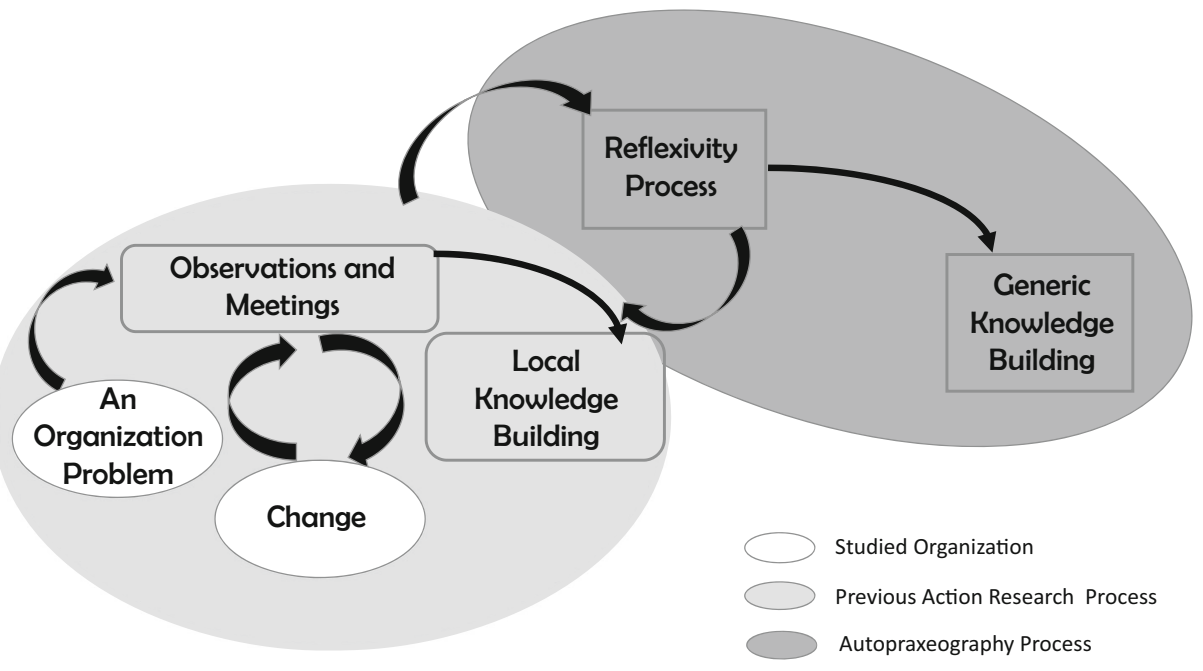

Fig. 1 The methodological process

\section{Pragmatic Constructivism Epistemological Paradigm}

The case studied in this article is anchored in the pragmatic constructivism epistemological paradigm (Avenier and Thomas 2015), thus labelled by Avenier (2011). This paradigm is very close to radical constructivism such as conceptualized by Von Glasersfeld (2001), Vico and James and Piaget (cited in Avenier 2010). In this epistemological paradigm, knowledge neither pretends to reflect an ontological reality (because nobody can prove its rational existence) nor does it reveal its characteristics when this reality exists. This constructivism is not so extreme that it rejects the notion of essence in its entirety (Grint 1998). In this paradigm, while knowledge in being built, there is no difference between the investigator and the phenomenon being investigated. They simply cannot be distinguished because the product-from the viewpoint of the observer (an explicit or implicit theoretical hypothesis) -influences the observations. Pragmatic constructivism believes that truth has no meaning because of how knowledge is built (from human representations in order to give meaning to situations in which people are involved). Consequently, the production of knowledge does not mean that we have a faithful representation of reality, but rather that it gives us the means to understand life.

This paradigm uses an abductive approach, which is defined by Banathy and Jenlink (2005). It works "through interpreting or re-contextualizing individual phenomena within a contextual framework, and aims to understand in a new way, from the perspective of a new conceptual framework. [...]. In this process, data is collected simultaneously to theory building which implies [...] a 'back and forth' direction between theory and empirical study" (p. 138). This approach introduces intuition into the scientific approach (Kovács and Spens 2005).

To legitimize knowledge, this paradigm uses reflexivity. Reflexive work is what researchers do when they behave as reflexive practitioners of scientific research. It consists of tracking what seems self-evident and digging into both the implicit assumptions and the deep meaning of the notions that are used or newly introduced. The researcher often uses a large body of academic literature to understand local knowledge, not to seem scientific but to stand back and understand it differently (Albert and Couture 2014). 


\section{Action Research}

Action research is a fertile way of narrowing the gap between the researcher and practitioner (Ripamonti et al. 2015). We use Reason and Hilary (2001) definition for this method as described at the beginning of the Handbook of Action Research:

[A] participatory, democratic process concerned with developing practical knowing in the pursuit of worthwhile human purposes, grounded in a participatory worldview which we believe is emerging at an historical moment. It seeks to bring together action and reflection, theory and practice, in participation with others, in the pursuit of practical solutions to issues of pressing concern to people and more generally the flourishing of individual persons and their communities (p. 1).

This method has two objectives: to provide some guidelines for practitioners who experienced some difficulties and to advance science (Babüroglu and Ravn 1992). In order to contribute to theories about the change process (Walton et al. 1989), in this method, knowledge is socially constructed, and research is embedded in a system of values that promotes human interactions (Brydon-Miller et al. 2003). However, many researchers in action research build theories to apply them, which is what practitioners expect. They emphasize the transfer of knowledge rather than a real collaborative engagement (Ripamonti et al. 2015).

Our action research process was carried out a few years ago. It helped the human resources manager to develop a dialogue and create a starting point for a community of persons. We took numerous notes during this process (interviews, meetings, observations, emails, etc.) and wrote a report at the end of the mediation phase. By using autopraxeography, we were able to produce generic knowledge.

\section{Autopraxeography}

Autopraxeography (Albert and Michaud 2016) is a self-study method.

\section{Self-Studies}

Using researchers' experiences to produce knowledge is more and more frequent in social sciences (Albert and Michaud 2016). Even if it is not so developed in management sciences, Boje and Tyler (2009) and Haynes $(2006,2011)$ use auto-ethnographies, and introspection is emerging in consumer research (Gould 2012). Various kinds of similar approaches exist under different names: autobiography, auto-ethnography, introspection, personal narratives, selfstudies, personal experience narratives, self-stories, first-person accounts, personal essays, auto-observations, personal ethnography, reflexive ethnography, and testimonio, among others. Researchers do not agree on the definitions of each of these approaches Ellis and Arthur 2003). Contrary to other kinds of studies, here, researchers seek to make sense of personal experiences by using these reflexive methods.

The use of autobiographical methods may be perceived as "insufficiently rigorous, theoretical, and analytical" (Ellis et al. 2011, p. 11) by scientific standards (in a positivist way). "Self-study researchers have also exhibited the need to wrestle with the question of the validity of their studies" (Feldman 2003, p. 26). Even if these methods seem to have no scientific content (Holbrook, Moris. B. 1995; Chris 2007; Rod 2011), it is more important to be relevant with regard to the epistemological paradigm that has been chosen. For this reason and to help 
legitimize it, this kind of method has to be developed within a non-positivist paradigm. In the paradigm of pragmatic constructivism, research legitimizes knowledge through reflexive work (Albert and Avenier 2011). In this case, knowledge is not found in the narrative, but is built from it.

Autopraxeography is the counterpart of auto-etnography with a large spectrum of investigation. This method was used when one of the co-searchers had a particular experience that could be inquired into by using a large body of literature to produce generic knowledge (Albert and Michaud 2016).

\section{Autopraxeographies Specificities}

First, Albert and Michaud (2016) show that this method has three characteristics. They start by demonstrating that knowledge built from autopraxeographies are neither nomothetic nor idiographic. Usually self-studies are conceived in an idiographic perspective. In this perspective, knowledge built from practices is viewed as local knowledge (Tsoukas 2005). The pragmatic constructivism epistemological paradigm produces generic knowledge that diverges from both idiographic and nomothetic perspectives. Generic knowledge is not a generalizable knowledge; it has to be contextualized again in each new situation (Avenier 2010).

Then, based on Avenier and Thomas (2015), Albert and Michaud (2016) explain that the quality of autopraxeographies depends on the quality criterion of an abductive explanatory case study in pragmatic constructivism, that is, "the quality of inferences depends on the intelligibility and cogency of reasoning used in building the model from the empirical material" (p. 80). So, the autopraxeography process consists of a successive back and forth between practice and theory. The use of multiple and varied literature makes it possible to critically and knowledgeably improve the construct (Le Moigne 1990). This step back, by using theories, supports the transformation of narratives (local knowledge) into generic knowledge.

Finally, contrary to most of self-studies, autopraxeography requires that testimonies be written in the past tense for researchers to separate themselves from the moment of their experience. They take the point of view of an outsider-expert. This step back supports the emergence of the beginning of an abductive process. This reflexivity leads to rewriting some parts of their testimony by focusing on parts or points of view that were forgotten. This kind of writing helps researchers put a distance between themselves and their experiences (Albert and Michaud 2016).

\section{Autopraxeography Process}

There are several steps to this method. First, researchers write their testimony in a naïve way, as a practitioner, like talking about their day when they get home from work or recounting holidays to a friend. Then, after revisiting their testimonies with theories, researchers generate reflexive works.. Practitioner-researchers use this opportunity to examine their narrative several times to find and develop what was initially implicit or unconscious. To accomplish this, researchers must compare and contrast personal experiences against existing multidisciplinary research. This back-and-forth motion enables researchers to develop generic knowledge that can be activated in other contexts (Albert and Michaud 2016).

In our case, in order to write the testimonies, we read our previous notes and report and interacted a few times with a previous collaborator. The reflexive work (with one of the 
coauthors who did not have the same experience, or all the theoretical text read by all of us) inquired into testimonies. This way, we added the information needed to delve deeper and continued our process.

\section{Some Method Limits}

When using biographical methods in research, we must also consider that there are undoubtedly limits to our knowledge of the past due to subjectivity, and even authors (who are the protagonists of their own story) are subject to these limits (Santos and Garcia 2006). While trying to be as sincere as possible, everything is not related or even relatable. Moreover, memory can be limited and transform how we view past actions. So, it is important to emphasize the study of the past from the point of view of the present as Mead's work suggests (cited in Albert and Couture 2014). Given our epistemological choice, the purpose of the narrative is not to represent the truth, but to prepare the ground in which to sow one's reflexive work and produce knowledge to help understand life. The raw material that is the reconstruction of the past from the present of just one person does not produce scientific knowledge; it is all the reflexive work on it that produces it. A limit of self-studies is that they provide only one source of empirical information. Each self-study consists of a single point of view, which is limited and anchored in a geographical and institutional context. Reflexive work made with a large spectrum of literature reduces the effects of this limit. The scientific knowledge produced is not the testimony itself, but the reflexive work. The academic literature used during this process stems from various contexts. As shown in Fig. 1, the reflexive process was used on the previous action research, to produce generic knowledge.

\section{Advantages of Using these Methods for this Study}

In view of the action research process, it is important to note that the researcher spent time and worked in this organization. This period and the understanding of work and realities helped develop trust, which in turn supported a better understanding of the connections between the different persons in the organization. The use of autopraxeography enabled us to step back from the previous action research experience on two levels. First, in an abductive process, this case was viewed from a new perspective (the community of persons); autopraxeography provided access to some past experiences through a back-and-forth motion between the experience and theories. Second, autopraxeography let us step back from the present emotion. Decentering helped identify the coherence of previous actions.

\section{Case Study Presentation}

This case study took place in a business organization where many conflicts arose. This organization was part of a larger one located on an island, where unions had a lot of power, and union workers managed to block activities several times. Generational conflicts existed between operators, there was an absence of hierarchical structure (the foreman position remained vacant for 18 months), and work rules were not respected, even for personal safety. At this time, the executive management's mandate was to pacify work relations and restore communication and common sense. The HR manager told us his expectations concerning our intervention (within the action research process), linking it to his own mission in this company. He wished to develop a long-term strategic HR approach that could resist the test of time. The 
HR manager thought that company growth depended on the development of healthy and respectful relationships. He could see the difference between this long-term vision (strategic) and short-term actions (tactical). However, long-term actions were presently setup within a strained context. Our own objective was to learn about the context as much as possible in order to build the founding blocks of long-term HR development, which would become the company's cornerstone.

\section{Case Study and Its Reflexive Work}

The case study has been presented in three parts. Each separation corresponds to a period of time.

\section{The Initial Situation: Conflict}

\section{Case Study}

Before we arrived, the HR manager explained the situation: an employee hit his colleague with an iron bar and chased him into the director's office. The group of employees also mentioned that there was no foreman for 18 months, even though this was considered to be a vital link in the organization of the team's manual work. From its point of view, the executive management considered that employees were fighting against achieving objectives with nonprofessional and sometimes aggressive behaviours. The executive management noted that the company provided operators significant material stuff in order to achieve easily their tasks and to reach their objectives. As a subsidiary company located on an island, the executive management depended on the flexibility given to them by the national branch. It had no more financial resources and didn't want to offer higher wages. Consequently, antagonists became focused on numerous groundless claims. This situation could escalate into a strike that might threaten all of the players involved.

\section{Reflexive Work}

In cases of industrial disputes, it is hard to find common ground, but there is a common object: the dispute. In this context, nonviolent communication (Rosenberg 2005) and negotiation (Fisher and Ury 1981) are relevant since they free individual expression within the group. Communication (Sabourin and Antona 2003) is a tool that allows room for reciprocity, trust, and cooperation. When using this tool, the conflict transforms into an opportunity to base a common ground in rationality (Boyle 2003). In our case, the organization did not function as a community of persons, but as an association, which is a group of individuals led by their individual aspirations and calculations, and who are bound to one another by contract (Naughton 2015). In an association, there is no openness; each person follows their own rationality, has their own background, and does their own work. The organization represents income security, what is in common. It is governed by common rules that define the organization's outcomes (Ostrom and Barsuto 2011), but that also act as an obstacle work against individual and collective efficiency by trying to reach business objectives. The "arenas of action" where our intervention rested, had one purpose: to change the rules defining outcomes in order to be once more flexible when trying to reach objectives. Otherwise, the 
organization risked becoming stiff and no longer able to produce space for negotiation and discussion. In such cases, a gap appears between the official work and the actual work (Leplat 1997), and the relationships between those involved end up individualizing the whole organization and its components. In our case, the disintegrating cohesion among employees and the individualizing rationality threatened to collapse the organization. This demonstrated the extent to which this organization was, at that time, an aggregate of individuals rather than a community of persons. Everybody seemed motivated only by their own goals, calculations and bound by contracts (Naughton 2015). Communication and dialogue stopped altogether, and the manager called mediators in to start the process up again. This absence of dialogue could be partially explained by the differences between blue-collar and white-collar employees. It is well known that recognizing class differences reinforces a feeling of belonging to a class (Horton et al. 2014); in a class culture, it is easier to see otherness than identity, and this egocentric closure makes all "others" become "foreign" (Morin 2008).

\section{During the Action Research: Mediation}

\section{Case Study}

When we arrived, we saw a different situation than what the HR manager presented. First, the managers had mentioned various violent acts between employees and the fact that new employees were not really integrated into the teams. It was a rather masculine culture of work, and there was real solidarity inside each team, even the new ones. Second, there were still conflicts: there were difficulties between employees and managers, and between teams (each team did the same work at different moments, one in the morning and the other in the afternoon). For instance, teams did not feel respected by the other teams (the workstation, toilets, and common spaces were dirty). And employees were distrustful of managers. The first day we arrived, a manager offered employees croissants to try to open a dialogue while explaining who we were. Although they seemed to show some good faith toward employees, the employees didn't believe it was sincere and wanted to know what the managers were hiding.

We had to move forward in small steps. The trick was to have a clear strategy. We highlighted the importance of transparency with respect to the objectives, methods, and contributions of everybody involved. Concern with transparency is one of this study's ethical founding blocks. All action, all communication, and all perception are legitimate as soon as people and the clear and transparent approach are respected when reaching for a common goal. At first, we worked with people in pairs to raise the collective intelligence level, which is promoted through mutual trust. Then we mixed the groups for a day to work on a common production. We tried to give the floor back to each person. We took into account each discomfort experienced by everybody on everything. The freedom for all to express their own excessive emotions enabled group members to tighten their bonds with one another. This made it possible to develop a new sense of solidarity, and to go from "I" or a small "we" (each team) to a larger "we."

In order to increase creativity, we divided the big group into smaller groups, and gave them the following goals:

- $\quad$ Together, find 3 to 10 rules that are important for living and working as a team.

- Find one action that would really help implement these rules. 
We walked around to help the groups express their ideas, listen to each other, and build together a joint decision. At the end of the allotted time, two participants (one manager and one employee chosen by the group) were asked to report on what their group discussed. The groups successively explained how their opinions converged.

This dialogue highlighted a divergence on a special tool: a dashboard. Managers built this tool as it is usually taught: it measures each part of activities prescribed by management. Employees estimated that this tool wasn't able to measure all the coordination between different employees. This dashboard required that persons adopt individual behaviours which could seem counterproductive from a collective perspective. The dialogue between managers and employees showed that they disagreed about this tool, but also that they shared a vision. So, we explained to both groups that they were talking about the same things. Then, it was possible to build a new dashboard sharing both points of view (to measure activities and support collaboration). This move facilitated communication with employees who felt recognized as persons and as a community, which in turn fostered collaboration.

This dialogue was used as the basis for action and foundation for "the guide of best practices." Finally, the groups explained again their differences and their contribution to work.

From this vibrant debate emerged the 10 most essential points for their "agreement of best practices." The two symbolic actions that were chosen were effective and not too expensive:

- To review the functionality of the "toilet block."

- To create a think tank in order to improve the production line and ensure that production objectives do not reduce quality of life.

The actions that the work groups suggested (to facilitate the production line process in view of improving toilet functionality) were very far from what the executive manager had feared would be proposed. He had thought that the employees would ask for salary increases or expensive equipment. As a matter of fact, the executive management generally considered employees as being lazy and purposeless persons (a caricatured projection of Taylorism). For this reason, the executive management modified its own perceptions in order to see employees as business partners with whom they would be able to create commons. This involved every level of the hierarchy, people had to respect commitments and individuals, and a long-term communicative process had to be established. During this mediation, we talked about holoptism and collective intelligence as "the capacity of human communities to evolve towards higher order complexity and harmony, through such innovation mechanisms as differentiation and integration, competition and collaboration" (Atlee and Por 2000, p. 3). Holoptism or collective intelligence involves dialogue: "high quality information and access to experts can be combined with high quality dialogue and deliberation in a highly focused way to generate powerful collective intelligence with minimal expense" (Atlee 2010, p. 283). So holoptism means creating dialogue and commons.

The goal was to work on the idea of common objectives and the collaboration needed to attain them. This was inspired by the notion of collective intelligence, which suggests (according to an operator) the existence of a linguistic capacity to act and perceive, thus interacting with one's surroundings and producing meaning (Bonabeau and Theraulaz 1994). Intelligence is collective when a group is provided with opportunities to interact that enable people to correlate their behaviours in an adaptive manner in different situations (Bonabeau and Theraulaz 1994). Next, to harness collective intelligence, it is useful to create interactions between linguistic capacities (communication), perceptions (feelings) and action (toward 
common and personal objectives). These interactions are available and invested in a meaningful way. Thus, we shed light on the following principles:

- To develop different spaces in which groups can explore their communicative ability.

- To clarify perceptions.

- $\quad$ To find unifying actions.

- To personalize these actions and give them a collective meaning: preparing the ground for long-term HR strategies.

From this process emerged leaders, deliberation, dialogue, community conflict resolution and collaborative action that led to common consciousness and action.

The executive management and the assembly line operators produced an agreement on the "quality of work life" named "A.1.2.C.4" (that we could translate as "see you soon"). The name was suggested by an operator, according to whom the charter was a veil hiding difficulties. The HR director shook his hand, approved the name, and said, "this name will give it substance."

\section{Reflexive Work}

Meyer (1999) distinguishes two different traditional modes of masculine culture: respectable and rough. In our case, the employees' culture coincided with the rough mode. This culture promoted a "swaggering masculinity" (Meyer 1999, p. 117). In this context, men could activate some norms and behaviours that promote physical capabilities to resist to the low status attached to class and occupational positions (Slutskaya et al. 2016). But employees as automobile workers in Meyer's (1999) study maintained this masculine rough identity through a boy-like playfulness where crudeness is more symbolic than real. So, even if the situation appeared conflictual, it was just a symbolic show of a masculine culture of roughness. This culture promotes a strong egalitarianism and opposition to employers (Meyer 1999). Thus, employees were more than an association of individuals, and this culture confirms the obstacle of dialogue explained by the apparent class struggle showed in the previous section.

The dashboard monitors work tasks as they are prescribed. But the rules of collective work are more than just technical rules; they have an irreducible social dimension, especially as they challenge the prescribed coordination (Dejours and Deranty 2010). Moreover, the disjunction of each part of work from the other could appear as rational, but this rationality transforms into rationalization (Morin 2008). Instead of thinking in a reductionist way, Morin (2008) invites us to consider a conjunction pattern. The complexity of workplace interactions needs to look beyond the sum of each individual's tasks, and take into account unpredictability and collaboration between persons.

As with Wilson (2004), persons in this process listened "to the[ir] deepest faculty of inner knowing." Building dialogue builds commons, and commons bring dialogue. So, in an organization with a community of persons "dialogue can be deepened until we are listening beyond the words to our own and others' needs, feelings, assumptions and frames" (Wilson 2004, p. 6).

In order to build a community, people must work together. Respecting others, managers and employees could try to build a community and exceed the limits of employeeemployer contracts (Tablan 2014). These community choices are not rational from a market perspective, but they highlight the importance for each person to build a collaborative community (Adler et al. 2008). 
Contrary to management's expectations, and according to Ostrom (1990), employees as appropriators calculated that the long-term net benefits expected should be greater for all appropriators than if they just followed predominantly short-term strategies. So it was in their interest to become more moderate in their demands. Employees understand that all appropriators (themselves included) can be winners when "individuals follow rules and engage in mutual monitoring, reinforcing institutional arrangements and individual strategies bolster one another so as to maintain enduring patterns of consistent, but not perfect, rule-following behavior" (Ostrom 1990, p. 187). According to Perroux (1965), based on personalist Jean Lacroix's work, this social dialogue is commonly sought after, despite adverse communication, when looking for a fair solution. This dialogue entails the respect of others as well as long-term calculation. According to Bohm (1996), a dialogue connotes a flow of meaning through several persons as a collective and from which a new understanding can emerge. This dialogue suggests community, mutuality, and authenticity (Banathy and Jenlink 2005), and allows a "we" to come into being. This studied organization could be viewed as a community of persons (Naughton 2015) that becomes real to its members when persons feel like they belong to it, which is achieved through dialogue (Banathy and Jenlink 2005). To be able to describe and make sense, a person has to belong to a community and share and understand common experiences (Habermas 1985). So, if the HR manager was not in the community to make sense and give direction, if he was outside of the community, he was not contributing to the communicative action, but rather participating in the hierarchical constraint that reinforces antagonisms.

Collaboration and dialogue have parallel goals (Heath 2007). Helin and Avenier (2016), based on Bakhtin (1984), conceive dialogue as a perpetual struggle tendency between two forces: one centripetal and the other centrifugal. The first one drives unity, centralization, closure, and making room for consensus. The second tends to move away from the centre, toward openness and decentralization, making room for innovation, creation, multiplicities, and fragmentation. Thus, the centrifugal force is linked to the collective aspect of the community of persons, and the centripetal force is connected to the individual aspect. It therefore follows that dialogue is about developing and sharing differences between persons. This dialogical process is both about sharing commons and about multiple voices participating (Helin and Avenier 2016). So, dialogue may enable persons to be open to different ideas and to influence others (Chanlat 1990). In our case, dialogue made it possible to create a community; it created consensus (e.g., the dashboard). Dialogue is the expression of each person's point of view, and it is a process that changes over time. The agreement was written by all employees including the HR manager. Together, bound by their word, they committed themselves to respect the agreement (Gusdorf 1952). The HR manager gave his word as a person, but also as an organization representative. His word was his bond, and that of the organization. The new HR manager broke the moral and ethical commitment included in the agreement by failing to respect the undertaking (Habermas 1992). He revoked the mutual commitment and the bases for dialogue (Gusdorf 1952).

In our case, individuals formed a community of persons (Melé and Canton 2014) to enable the sustainable development of the organization. Respect for one another seemed important in order to progress together. This is an example of self-organized persons who managed to build a community of persons.

A person's duty cannot stop where the principle of duty for the sake of duty begins; it cannot stop where there is an action that can create a reciprocity agreement with others (Danese and Dinicola 1989). The "Golden Rule" (or "ethics of reciprocity") requires persons to put themselves in others' shoes (Maxwell 2003). 


\section{The end of the Adventure: Non-respect of the Agreement}

\section{Case Study}

When the HR manager left (1.5 years later), the agreement was forgotten (in this organization, all managers are renewed every four years). The new HR manager did not wish to "[lose] his time on this agreement." When he arrived, his mission was to prepare workers to accept the takeover of the organization expected a few months later. He tried to redirect the attention back on the previous sources of conflict: workstation cleaning, gap between morning and evening teamwork's, etc. He was hoping to divide any potential opposition. Despite the HR manager's attempts, employees wanted to preserve their unity and spoke with one voice. They were anxious to maintain a dialogue and the balance that previously existed. Employees decided to organize themselves informally to maintain their unity. They organized some informal discussions to regulate their group. Employees confronted the attempt to divide them as a group. They tried to obtain together some answers to the sales rumour. In 2014, the business buyout was announced. Operators were looking for information about the future of their employment. Without answers, operators and employees started a 10-day strike that paralyzed almost all of the island economy. For the record, the agreement documents were burnt on the front steps of the building, near the new director. The union leader said, "there remains only ashes of our social dialogue."

The new HR manager broke with the culture established by his predecessor. Formerly, the HR manager would advocate trust and dialogue in order to maintain good, lasting relationships. These relationships were necessary to keep the social dialogue open and develop conditions for an optimal and humanly responsible production. Even if it was difficult, we found a long-term management strategy that proved to be efficient economically (return of quality production), socially (no conflicts for 1.5 years), and quantitatively (improvement of production methods). And yet, the new HR manager reoriented his strategy toward short-term strategies, by seizing control of the dialogue, spaces, and authority to act. He cut off his employees when they tried to express themselves concerning the sale of the company.

\section{Reflexive Work}

According to Ostrom $(1990,2000)$, one of the principles of implementing commons governance concerns monitoring and graduated sanctions if someone violates rules. However, when the person who represents an important appropriator decides to stop self-organization, he or she is throwing away any previous gains. This destroys the community of persons, reigniting previous conflicts. Even if market-based, this governing of commons seems to be counterproductive, the apparent loss of time actually making the organization more efficient. An imposition of the hierarchy breaks the trust (Ostrom 2005) that was previously established. While it is hard to build trust, it is easy to disrupt it. This appears obvious, but it is often forgotten in practice. Respect, like that found in a community of persons (Melé 2012), was the core idea of the agreement; but it was not present in the new management. This new manager thought that a Leviathan could govern the common-pool resource and so he disrupted the agreement. However, in this case, it seems that the organization had nothing to share, there were no commons. Of course, persons should share resources and at least a few goals, but in a symbolic way they remain individuals standing next to one another. 
The head of the company forgot that an increased centralization generates, in the long run, some adverse effects (Ostrom 1990). Indeed, the long-term expected net benefits from a strategy encouraging credible commitment and mutual monitoring "are greater than the long-term expected net benefits for individuals following short-term, dominant strategies" (Ostrom 1990, p. 186). For Pirson and Lawrence (2010), the "economic man" engages only in short-term transactions because he responds to opportunities. At its extreme, it is a predatory behaviour often founded on individualistic premises. In contrast, humanist philosophers envision the long-term relationships with others as a central element for human beings, a condition stemming from "being together" in this world. Management, as Melé (2009c) points out, is often guided by the idea that each person is different and must be treated according to his or her qualities and personality. Even if these concepts apply mainly to the management of talents, it is possible that they will become the key to the organization's success, leading to humanistic and economic approaches complementing each other (Pirson and Lawrence 2010). This new HR manager referred to the economic rationality as the supreme norm of the organization (Chanlat 1990). Communication is the primary activity of a manager, especially for a Human Resources manager. As Chanlat (1990) highlights, failure in communication is painful for those concerned and costly for the company as a whole.

The decision to overlook the agreement made the employees think that the executive management would not trust them. However, trust is essential in cooperation; trust in others and believing that reciprocity is present (Gambetta 1988). Social dialogue is fragile; it rests on communication and moral behaviours (Perroux 1965). The executive management's behaviour broke this dialogue. By putting a stop to dialogue, this new HR manager stopped seeing the organization as a community. Even if he tried to divide this community, he just managed to develop a community of employees, who had come to learn that dialogue was important for continuity (Banathy and Jenlink 2005). The dialogue implemented during our action research showed employees the advantages of this kind of management. Employees were therefore motivated to maintain a community between them since they judged the situation to be unfair. Under these circumstances, employees could not feel included in an authentic community with persons representing the employer (Perroux 1938). While wanting to divide the existing community, the HR manager actually reinforced the community of employees. Because he was not part of it, he could not give meaning to the community (Habermas 1985). By so doing, he expanded the idea of responsibility among the employees.

Several theories link freedom to responsibility and obligation, and underestimating the part of the other. This way of thinking can generate a form of ethical promotheism that may create heroes, but would not offer room for reciprocity in relationships (Danese and Di Nicola 1989). A previous and always new enemy of ethical personalism is the utilitarian economism that promotes the calculation of advantages and disadvantages (i.e., damages and profits) to obtain the maximum benefit with minimum energy (Danese and Dinicola 1989; Melé 2009b). Reference to the notion of person does not lead to denying the value of economic rationality; it is more for integrating several rationalities than for referring to the integrality of the person (Danese and Di Nicola 1989). According to Pirson and Lawrence (2010), "blended value models show how the economic system can be reconnected to its humanistic root" (p. 563). Mounier (1936) explains that taking away what is human in work can lead proletarians to rebel (e.g., when workers are confined in their specialty by a division of labour not accompanied by compensatory participation in the administration of the whole).

Back to our case, the community of employees was disappointed and disillusioned. They rebelled against the employer's decisions. Mounier (1936) proposes to reconstitute natural 
communities with persons and develop organizations as communities of persons. In the case at hand, the executive management's decision generated many costs, hidden or not, like strike (no production and unsatisfied customers), stress (Fortier and Marie-Noëlle 2015), and distrust (Falk and Michael 2004). So, even if the manager seemed to be rational and productive, in reality, his decision was counterproductive for the organization. Time required to have a dialogue is neither wasted nor is it unproductive, it could make it possible to develop the sense of belonging to a community of persons.

\section{Conclusion}

This paper explored the concept of community of persons as proposed by Naughton (2015) by using a case study. The in-depth analysis of this case highlights the importance of dialogue. Melé (2012) concludes that a community of persons requires an appropriate communication. The case presented above continues and goes beyond this idea. The concept of dialogue develops the idea of an appropriate communication.

In short, this case underlined dialogue, collaborative action and community conflict resolution to create commons. In relation to the first and the third parts of the case, there was no dialogue between managers and employees. There was only top to bottom information. This absence of dialogue sparked dissension and division between actors in the organization. In the second part, actors became persons with relationships and commons. Organizations consist of persons who collaborate in a community. So a community does not create commons without dialogue and personal engagement. Persons may work in the same organization, but without the presence of dialogue or without being part of the community, it is impossible to build commons. This process of building commons includes the possibility of conflicts arising. In our case, persons improved their inner knowing and mutual trust with collective intelligence, respect of persons and values, dialogue throughout the learning process, and collaborative actions. Dialogue has two forces: centrifugal and centripetal (Bakhtin 1984). Dialogue could generate consensus and conflicts were not experienced as a trial of strength; conflicts became opportunities to build common solutions. Dialogue made it possible to share common goals in maintaining each participant's sense of individuality as promoted by Melé (2009a). A real dialogue facilitated both a person's autonomy and ability to interconnect (Melé 2016). Finally, authentic human relations (Tablan 2014) foster dialogue.

As presented in the initial situation and the end of the adventure, there is a link between the absence of dialogue and an aggregation of individuals (Melé 2012). The establishment of dialogue fosters the sense of community and vice versa in a recursive way (Morin 2008). Indeed, to develop dialogue, we need to be open to others toward who this openness is directed.

When persons have the feeling of not being listened to, this is not consistent with viewing the organization as a community of persons; and, in our case, the organization reverted to an association of individuals. This is typical of what happens in many organizations. Managers want their employees to be committed, to build a team, but in reality these persons do not want to share with other employees. How can commons be managed if persons have nothing in common? Organizations have to invest a lot in order to develop the idea of "working together." In our case, both rules-monitoring of employees' respect and openness to others - made it possible to manage the commons of an organization. Without this, organizations could seem rational and efficient while generating a lot of hidden costs and becoming less 
efficient. In this paper, we showed that in order to build a community of persons, one needs time, space, and openness to others in order to have a dialogue.

It may be that the complexity of organizations and current challenges, instead of highlighting a paradox, reveal a dialogy: on the one hand, the necessary independence of persons in the workplace (Tremblay and Nadia 2015) and, on the other, interdependencies in action (Azaïs 2006). This may encourage managers to exercise their authority as leaders, but would they do it at the expense of the power they wield as "bosses"?

\section{References}

Adler, Paul S., Seok Won Kwon, and Charles Heckscher. 2008. Perspective-professional work: The emergence of collaborative community. Organization Science 19 (2): 359-376.

Albert, Marie-Noelle, and Marie José Avenier. 2011. Légitimation de savoirs élaborés dans une épistémologie constructiviste à partir de l'expérience de praticiens. Recherches qualitatives 30 (2): 22-47.

Albert, Marie-Noëlle, and Marie-Michèle Couture. 2014. To explore new avenues: Experiential testimonio research. Management Decision 52 (4): 794-812.

Albert, Marie-Noëlle, and Nancy Michaud. 2016. From disillusion to the development of professional judgment: Experience of the implementation process of a human complexity course. SAGE Open 6 (4): 2158244016684372.

Atlee, Tom. 2010. Integral Politics as Process. Integral Review: A Transdisciplinary \& Transcultural Journal for New Thought, Research, \& Praxis 6(1).

Atlee, Tom, and George Por. 2000. Collective intelligence as a field of multi-disciplinary study and practice. En ligne. http://www.community-intelligence.com/files/Atlee.

Attilio, D., \& de Nicola, G. P. (1989). Éthique et personnalisme. Louvain-la-Neuve: Ciaco.

Avenier, Maire-Josée. 2010. Shaping a constructivist view of organizational design science. Organization Studies 31 (9-10): 1229-1255.

Avenier, Marie-Josée. 2011. Les paradigmes épistémologiques constructivistes : post-modernisme ou pragmatisme? Management et Avenir 3 (43): 372-391.

Avenier, Marie-Josée, and Catherine Thomas. 2015. Finding one's way around various methods and guidelines for doing rigorous qualitative research: A comparison of four epistemological frameworks. Systèmes d'Information et Management 20 (1): 61-98.

Azaïs, Christian. 2006. Désegmentation du marché du travail et autonomie. In Travailler au XXIème siècle: nouveaux modes d'organisations du travail, ed. S. Bouteiller, 144-127. Bruxelles: De Boeck.

Babüroglu, Oguz N., and Ib Ravn. 1992. Normative action research. Organization Studies 13 (1): 19-34.

Bakhtin, Mikhail. 1984. In C. Emerson (Ed. and transl.), problems of Dostoevsky's PoeticsMinneapolis, MN: University of Minnesota Press.

Banathy, Bela H., and Patrick M. Jenlink, eds. 2005. Dialogue as a means of collective communication. New York: Kluwer academic/plenum publishers.

Bohm, D. (1996). In L. Nichol (Ed.), On dialogue. London: Roudedge.

Boje, David, and Jo A. Tyler. 2009. Story and narrative noticing: Workaholism autoethnographies. Journal of Business Ethics 84: 173-194.

Bonabeau, E., \& Guy, T. (1994). Intelligence collective. Paris: Hermes sciences publication.

Boyle, John. 2003. Foreword: The opposite of property? The public domain. Law and Contemporary Problems $66(1-2)$.

Brydon-Miller, Mary, Davydd Greenwood, and Patricia Maguire. 2003. Why action research? Action Research 1 (1): 9-28.

Chanlat, Jean-François. 1990. L'individu dans l'organisation: les dimensions oubliées. Québec: Presses Université Laval.

Chris, H. (2007). Auto-ethnographic consumer research and creative non-fiction: Exploring connections and contrasts from a literary perspective. Qualitative Market Research: An International Journal, 10(1), 98-108.

Dejours, Christophe, and Jean Philippe Deranty. 2010. The centrality of work. Critical Horizons 11 (2): 167-180.

Ellis, Carolyn, and Bochner Arthur. 2003. Autoethnography, personal narrative, reflexivity: Researcher as subject. In Collecting and interpreting qualitative materials, ed. N.K. Denzin and Y.S. Lincoln, 199-258. CA: Sage, Thousand Oaks.

Ellis, Carolyn, Adams Tony, and Bochner Arthur. 2011. Autoethnography: An overview. Forum Qualitative Sozialforschung / Forum Qualitative Social Research 12 (1): 273-290. 
Falk, Armin, and Michael, Kosfeld. 2004. Distrust-the hidden cost of control. ZA Discussion Paper No. 1203; IEW Working Paper No.193.

Feldman, Allan. 2003. Validity and quality in self-study. Educational Researcher 32: 26-28.

Fisher, R., \& Ury, W. (1981). Getting to yes: Negotiating agreement without giving in. Boston: Houghton Mifflin.

Fortier, Michel, and Albert Marie-Noëlle. 2015. From resource to human being. SAGE Open 5 (3): 1-13.

Gambetta, Diego. 1988. Trust: Making and breaking cooperative relations. Oxford: Blackwell.

von Glasersfeld, Ernst. 2001. The radical constructivist view of science. Foundations of Science 6 (1-3): 31-43.

Gould, S.J. 2012. The emergence of consumer introspection theory (CIT): Introduction to a JBR special issue. Journal of Business Research 65 (4): 453-460.

Grint, Keith. 1998. Determining the indeterminacies of change leadership. Management Decision 36 (8): $503-508$.

Gusdorf, Georges. 1952. La parole. Paris: Presses universitaires de France.

Habermas, Jürgen. 1985. The theory of communicative action (Vol. 2). Beacon press, Boston.

Habermas, Jürgen. 1992. L'espace public, 30 ans après. Quaderni: la Revue da la Communication 8: 161-191.

Haynes, Kathryn. 2006. Linking narrative and identity construction: Using autobiography in accounting research. Critical Perspectives on Accounting 17: 399-418.

Haynes, Kathryn. 2011. Tensions in (re)presenting the self in reflexive autoethnographical research. Qualitative Research in Organizations and Management: An International Journal 6: 134-149.

Heath, R.G. 2007. Rethinking community collaboration through a dialogic lens: Creativity, democracy, and diversity in community organizing. Management Communication Quarterly 21 (2): 145-171.

Helin, J., and M.J. Avenier. 2016. Inquiring into arresting moments over time: Towards an understanding of stability within change. Scandinavian Journal of Management 32 (3): 142-149.

Holbrook, Moris B. 1995. Consumer research: Introspective essays on the study of consumption. CA: Sage Publications Thousand Oaks.

Horton, K.E., P.S. Bayerl, and G. Jacobs. 2014. Identity conflicts at work: An integrative framework. Journal of Organizational Behavior 35 (S1).

Housset, Emmanuel. 2007. La vocation de la personne - L'histoire du concept de personne de sa naissance augustinienne à sa redécouverte phénoménologique. Paris: PUF.

Kovács, G., and K.M. Spens. 2005. Abductive reasoning in logistics research. International Journal of Physical Distribution \& Logistics Management 35 (2): 132-144.

Leplat, J. (1997). Regards sur l'activité en situation de travail: contribution à la psychologie ergonomique. France: Presses universitaires de France.

Maxwell, John C. 2003. There's no such thing as "business" ethics: There's only one rule for making decisions. New-York: Warner.

Melé, Domènec. (2009a). 7 Current trends in humanism and business. In Heiko Spitzeck, Michael Pirson, Wolfgang Amann, Shiban Khan, and Ernst von Kimakowitz (2009a). Humanism in business. Cambridge: Cambridge University Press, 123-139.

Melé, Domènec. 2009b. Integrating personalism into virtue-based business ethics: The personalist and the common good principles. Journal of Business Ethics 88: 227-244.

Melé, Domènec. 2009c. Business ethics in action: Seeking human excellence in organizations. Basingstoke, Hampshire: Palgrave Macmillan.

Melé, Domènec. 2012. The firm as a "community of persons": A pillar of humanistic business ethos. Journal of Business Ethics 106 (1): 89-101.

Melé, D., \& Gonzalez Canton, C. (2014). Human foundations of management: Understanding the homo humanus

Melé, Domènec. 2013. Antecedents and current situation of humanistic management. African Journal of Business Ethics 7 (2): 52.

Melé, Domènec. 2016. Understanding humanistic management. Humanistic Management Journal 1 (1): 1-23.

Meyer, S. 1999. Work, play, and power: Masculine culture on the automotive shop floor, 1930-1960. Men and Masculinities 2 (2): 115-134.

Mintzberg, Henry. 2009. Rebuilding companies as communities. Harvard Business Review 87: 140-143.

Le Moigne, Jean-Louis. 1990. La modélisation des systèmes complexes. Paris: Bordas, Dunot.

Morin, Edgar. 2008. On complexity. NJ: Hampton Press.

Mounier, Emmanuel. 1936. De la propriété capitaliste à la propriété humaine. Desclée de Brouwer.

Mounier, Emmanuel. 1952. Personnalism. Notre Dame: University of Notre Dame Press.

Naughton, Michael. 2015. Thinking institutionally about business: Seeing its nature as a community of persons and its purpose as the common good. In Humanism in economics and business 179-199, ed. D. Melé and M. Schlag. Netherlands: Springer.

Ostrom, Elinor. 1990. Governing the commons: The evolution of institutions for collective action. Cambridge: Cambridge university press. 
Ostrom, Elinor. 2000. Reformulating the commons. Swiss Political Science Review 6 (1): 29-52.

Ostrom, Elinor. 2005. Understanding institutional diversity Princeton University press. New: Jersey.

Ostrom, E., \& Basurto, X. (2011). Crafting analytical tools to study institutional change. Journal of Institutional Economics, 7(3), 317-343.

Perroux, François. 1938. Capitalisme et communauté de travail. Revue de Métaphysique et de Morale 45 (4), 18-19.

Perroux, François. 1965. La pensée économique de Joseph Schumpeter: les dynamiques du capitalisme (Vol. 34). Librairie Droz.

Pirson, M. A., \& Lawrence, P. R. (2010). Humanism in business-towards a paradigm shift? Journal of Business Ethics, 93(4), 553-565.

Reason, Peter, and Bradbury Hilary, eds. 2001. Handbook of action research: Participative inquiry and practice. London: Sage.

Ripamonti, Silvio, Galuppo Laura, Gorli Mara, Scaratti Giuseppe, L. Ann, and Cunliffe. 2015. Pushing action research toward reflexive practice. Journal of Management Inquiry 25 (1): 55-68.

Rod, Michel. 2011. Subjective personal introspection in action-oriented research. Qualitative Research in Organizations and Management: An International Journal 6: 6-25.

Rosenberg, Marshall. 2005. Les mots sont des fenêtres (ou ce sont des murs). Paris: Initiation à la communication non-violente. La découverte.

Sabourin, Eric, and Martine Antona. 2003. Action collective et développement. France: Acte du séminaire permanent d'action collection. CIRAD Colloques. Montpellier.

Santos, V., \& Garcia, T. (2006). Managers' opinions: reality or fiction: a narrative approach. Management Decision, $44 n^{\circ} 6,752-770$.

Slutskaya, Natasha, Jason Hughes, Alexander Simpson, and Selçuk Uygur. 2016. Masculinity and class in the context of dirty work. Gender, Work \& Organization 23 (2): 165-182.

Tablan, Ferdinand. 2014. Ethical implications of Catholic social teachings on human work for the service industry. Journal of Religion and Business Ethics 3 (1): 11.

Tönnies, Ferdinand. 1887. Community and society. The urban sociology reader 13.

Tremblay, Diane-Gabrielle, and Lazzari Nadia. 2015. Emploi et gestion des ressources humaines dans l'économie du savoir. Québec: Presses de l'Université du Québec.

Tsoukas, Haridimos. 2005. Do we really understand tacit knowledge? 107-126. An Essential Reader: Managing Knowledge.

Vernant, Jean-Pierre. 1996. Mythe et pensée chez les grecs. Paris: La Découverte.

Walton, Ricard E., E. Michael, and Gaffney. 1989. Research, action, and participation: "the merchant shipping case". The American Behavioral Scientist 32 (5): 582.

Wilson, Patricia A. 2004. Deep democracy: The inner practice of civic engagement. Fieldnotes: A Newsletter of the Shambhala Institute 1(3). 